\title{
Behavioral correlates of reproductive success in a pigtail macaque breeding colony
}

\author{
L. A. FAIRBANKS \\ University of Washington, Seattle, Washington 98195
}

\begin{abstract}
Data on social and spatial behavior from a sample of 21 female pigtail macaques (Macaca nemestrina) were analyzed to identify behavioral correlates which could be used to predict reproductive success, problem pregnancies, and adult female mortality in a primate breeding colony in the subsequent year. Two spatial measures of sociability, amount of time and number of other individuals involved in sitting associations, were found to be related to future adult and infant survivorship.
\end{abstract}

With the rising interest in the development of breeding colonies for primates in the United States, there is a strong need for information relating to reproductive success under colony conditions. Van Wagenen (1972) has used the breeding records from a rhesus macaque (Macaca mulatta) colony to describe characteristics of successful births, abortions, stillbirths, early neonatal deaths, and maternal deaths. Sackett, Holm, and Landesman-Dwyer (1975) analyzed breeding colony records for pigtail macaque (Macaca nemestrina) females. They found that the weight of the mother, medical treatment history, number of years in the colony, number of days in a stable breeding group, and previous reproductive history all correlated with pregnancy outcome and could be used to predict the success of future pregnancies at a better than chance rate. Analysis of squirrel monkey (Saimiri sciureus) breeding records has shown that length of time in the colony and diet are important factors in reproductive success in this species (Rosenblum, 1968).

While these studies seem to indicate a trend toward greater use of breeding colony demographic and medical records, there still is a paucity of behavioral data to aid in understanding the determinants of pregnancy outcome in primates. Long-term studies of free-ranging rhesus monkeys on La Parguera indicate that behavioral differences between females are correlated with differences in reproductive success, with infants of higher ranking females having a greater chance of surviving than infants of lower ranking females (Drickamer, 1974). Similar studies relating reproductive success to the particular conditions of the breeding colony are lacking, however.

The author would like to thank Dr.G. Blakley, Dr. W. Morton, and Mr. W. Ross at the Medical Lake Primate Field Station for their cooperation in allowing access to their breeding groups and colony records, and Mr.S. Cole and Dr. G. Sackett for helpful criticism on the manuscript. This research was supported by a National Science Foundation graduate fellowship. Richard $\mathrm{H}$. Bauer sponsors the paper and takes full editorial responsibility for it. Address reprint requests to L. A. Fairbanks, PhD, Department of Psychiatry, Neuropsychiatric Institute, UCLA, Los Angeles, California 90024.
During the course of another study (Fairbanks, Note 1), data on social behavior were collected on several pigtail macaque females from the breeding colony of the Northwest Regional Primate Research Center; these data indicated that sociospatial interactions may be useful predictors of colony reproductive success. The purpose of the present paper is to describe the behavior of this sample of females as it relates to future maternal and infant survivorship in order to identify behavioral syndromes which may be diagnostic of breeding success and failure.

\section{METHOD}

\section{Subjects}

Subjects in the present analysis were 21 adult female pigtail macaques, all feral born and all members of social breeding groups at the Northwest Regional Primate Center Field Station, Medical Lake, Washington.

\section{Data Collection}

Subjects were observed during a 6-week period in June and July 1972, and during 3 months between January and April 1973. During these observation periods, the 21 subject females were members of 5 stable breeding groups, each containing 1 adult male and 4-7 adult females. (An additional six females were removed from their respective groups for experimental treatment in the year following observation and, thus, were not included as focal subjects in the present analysis.) The groups were all housed in similar rooms $7 \times 11 \times 8 \mathrm{ft}$, with shelves along the wall and pipes in the ceiling for sitting perches and visual access through a mesh door.

Data on each group member were collected during daily observation sessions where each individual was observed as focal animal for $5 \mathrm{~min}$. Half of the observation sessions for each group were held in the morning between 8:00 and 12:00 and half in the afternoon between 12:00 and 16:00. Over the entire data collection period, there was a total of $74.25 \mathrm{~h}$ of observation with the 21 subject females as focal animals.

Information on spatial relationships was obtained by recording the position of the focal animal as solitary, near (within reach), or huddled (in gross body contact) with other group members. Social interactions were coded in the following categories: social grooming, submissive behavior (including lip smack and fear grimace) and aggressive behavior (including hit, threat, physical attack, and spatial displacement). The behavioral code, the identity of the interacting animals, and the direction of each behavior were recorded, along with the spatial data, in 5-sec intervals on a data sheet. 
In order to facilitate analysis, the behavioral and spatial data were organized into the following six indices. (1) Time spent near: The percentage of 5-sec intervals in which the focal animal was within reaching distance of at least one other animal was used as a measure of spatial sociability. (2) Number of associations: An association was recorded for any pair of females who each reciprocally spent at least $10 \%$ of their timed intervals near or huddled with each other. Number of associations, therefore, is a spatial measure of the range of associations, or number of "friends," that each female had within the group. (3) Social grooming: The percentage of 5-sec intervals during which each focal animal was involved in social grooming, either as the initiator or the recipient, was used as a behavioral measure of affiliative interactions with other group members. (4) Frequency of wins: This measure was derived by combining the number of times the focal animal either aggressed against another animal or was the recipient of submissive behavior from another animal. (5) Frequency of losses: This measure is the converse of the above, i.e., it was derived by combining the number of times the focal subject submitted to another animal or was the recipient of aggression by another animal. (6) Relative dominance: Relative dominance was measured by the proportion of other females in the social group that each focal subject could displace. This was found to be the best measure of dominance in baboons (Papio anubis) by Rowell (1966) and produced a relatively clear-cut linear dominance order in the pigtail groups studied here.

Colony records were obtained for 1 year following the termination of data collection for each subject female to determine the survivorship of the females and any offspring born to them during this time period. These records were divided into three categories: Viable infant-females who bore viable infants which were still alive at the end of the year; nonviable infantfemales who did not conceive, suffered miscarriages, delivered stillborn infants, or whose infants died shortly after birth; female death-females who died from nonexperimental causes due to disease or traumatic injury.

Table 1 lists the identity of each female, the number of observation sessions, and the fate of her or her infant in the year following data collection. It should be noted that only two of these females required medical treatment during the course of observations. N3 was removed from the group for a period of 1 week for treatment of a gastrointestinal infection, and $L 1$ was removed for 4 days for treatment of a bite wound.

\section{RESI.JTS}

Following the data collection period, the results were organized into the six spatial and behavioral indices and compared for each of the three reproductive success (RS) categories. One-way analysis of variance was used to test for mean differences between the groups.

Table 2 -shows the mean and variance of the three RS categories for each behavioral index. There was a significant relationship between pregnancy outcome and the amount of time spent near other individuals $(F=8.91$,
Table 1

Identity, Number of Observation Sessions, and Reproductive History After 1 Year

\begin{tabular}{lcl}
\hline ID & $\begin{array}{c}\text { Number of Obser- } \\
\text { vation Sessions }\end{array}$ & \multicolumn{1}{c}{ Colony Record After 1 Year } \\
\hline P1 & 33 & Infant living \\
B1 & 64 & Infant living \\
T3 & 60 & Infant living \\
T4 & 54 & Infant living \\
W4 & 54 & Infant living \\
S4 & 54 & Infant living \\
L4 & 54 & Infant living \\
F1 & 33 & Female did not conceive \\
N1 & 33 & Infant dead-dehydration \\
L2 & 32 & Infant dead-traumatic \\
F2 & 32 & Infant dead-pneumonitis \\
S3 & 30 & Infant dead-pneumonitis \\
N3 & 60 & Infant stillborn or aborted \\
B4 & 43 & Infant stillborn or aborted \\
S5 & 44 & Infant stillborn or aborted \\
L1 & 33 & Female dead-traumatic \\
P2 & 32 & Female dead-endocrine disorder \\
S2 & 32 & Female dead-colitis \\
F4 & 26 & Female dead-traumatic \\
P5 & 44 & Female dead-undiagnosed disease \\
T5 & 44 & Female dead-undiagnosed disease \\
\hline
\end{tabular}

$\mathrm{p}<.01$ ); females who later bore viable infants spent more time with other group members than females whose infants died or who died themselves. The females who bore living infants also associated with more other group members than females who suffered reproductive failure $(F=6.0, p<.05)$; the females who died following the study associated with the fewest other females, with none forming sitting associations with more than one other female.

In the social grooming index, there was a tendency for females who did not survive the year to be invariably low in the amount of time spent in social grooming, but this difference was not statistically significant. The three measures of agonistic behavior (wins, losses, and relative dominance) were all highly variable within groups and produced no significant differences between groups.

Combining the two measures which significantly differentiated between groups (time near and number of associations) in a regression equation produces a multiple correlation of $\mathrm{R}=.70$ with infant viability. Thus, these two measures aione can reduce chance variance in identifying successful females by half $\left(R^{2} \cdot=.49\right)$

Table 2

Behavior by Reproductive Success Category

\begin{tabular}{|c|c|c|c|c|c|c|c|c|c|c|c|c|}
\hline \multirow{2}{*}{$\begin{array}{l}\text { Reproductive } \\
\text { Success }\end{array}$} & \multicolumn{2}{|c|}{$\begin{array}{c}\text { Time } \\
\text { Near } \\
\text { \% Intervals }\end{array}$} & \multicolumn{2}{|c|}{$\begin{array}{l}\text { Associations } \\
\text { Number }\end{array}$} & \multicolumn{2}{|c|}{$\begin{array}{c}\text { Social } \\
\text { Groom } \\
\% \text { Intervals }\end{array}$} & \multicolumn{2}{|c|}{$\begin{array}{c}\text { Wins } \\
\text { Instances/h }\end{array}$} & \multicolumn{2}{|c|}{$\begin{array}{c}\text { Losses } \\
\text { Instances } / \mathrm{h}\end{array}$} & \multicolumn{2}{|c|}{$\begin{array}{l}\text { Relative } \\
\text { Dominance } \\
\% \text { of Group }\end{array}$} \\
\hline & $\overline{\mathbf{X}}$ & SD & $\overline{\mathbf{X}}$ & SD & $\overline{\mathbf{X}}$ & SD & $\overline{\mathbf{X}}$ & SD & $\overline{\mathrm{X}}$ & SD & & SD \\
\hline Infant Viable & 54 & 10.8 & 2.6 & .91 & 6.0 & 4.1 & 3.2 & 2.4 & 8.3 & 4.4 & .42 & .22 \\
\hline Infant Nonviable & 34 & 14.0 & 1.1 & 1.27 & 3.2 & 4.1 & 5.7 & 6.6 & 14.3 & 11.1 & .47 & .39 \\
\hline Female Death & 36 & 6.7 & 0.7 & .47 & 1.1 & 1.2 & 3.8 & 3.1 & 10.9 & 5.5 & .40 & .35 \\
\hline
\end{tabular}




\section{DISCUSSION}

In the present study, measures of spatial sociability produced consistent and reliable predictors of colony reproductive success. The seven females who bore viable infants in the year following data collection tended to spend about half of their time near other group members and formed consistent sitting associations with several other females in their groups. The females who had problems with pregnancy, or who bore live infants which died shortly after birth, tended to spend more time alone and to associate with fewer other females than successful breeders. The six females who died from disease and traumatic injury in the year following observations spent most of their time alone and associated with the fewest other females. Contrary to intuition, they were not the object of aggressive interactions any more than were females in other reproductive success classes. Instead they tended to avoid interactions of all kinds by remaining solitary.

These results differ from those found for rhesus monkeys on La Parguera (Drickamer, 1974) in that dominance position of the females did not correlate with pregnancy outcome and involvement in agonistic behavior was an indication of reproductive failure as often as of success. This difference may well be due to the different pressures and problems of adjustment encountered in a laboratory breeding colony and free-ranging population. A level of sensitivity to environmental stress which is adaptive in the field may well be detrimental to adjustment to colony conditions. Behaviors which characterize dominant animals and correlate with reproductive success in a free-ranging population, such as aggressiveness and self-assertion, may be counterproductive in a confined laboratory breeding group, while other factors, such as tolerance, resistance to stress, and the ability to form affiliative bonds in a wide range of circumstances, may be more advantageous in the laboratory than in the field. One indication that this may be the case lies in the scores of the group of females who had nonviable pregnancies; members of this group either exceeded or tied the highest and lowest score in the sample on virtually every measure. Thus, females who tended to be the most extreme in their responsiveness to colony conditions also had more difficulty in successfully bearing and rearing young than females with a more moderate behavioral adjustment.

Another reason why spatial associations produced more reliable results than behavioral indices may be due to the relative duration and frequency of the two kinds of measures. The short duration and low frequency of agonistic episodes leads to an underestimation of their potential importance in group relations in a time sampling system. Many hours of continuous observation are required to achieve a reliable estimate of a behavioral event which may only occur for a few minutes once every few days. Spatial relationships, on the other hand, provide an ongoing record of group dynamics based on the individual members' perception of their relationships with each other. Thus, an agonistic episode which lasts only a few minutes and which has a low probability of being included in a sample will be continuously reflected in the change in spatial relationships which follows. Rather than indicating that agonism and dominance relationships are not important in colony reproductive success, these data suggest that spatial measures may be a more efficient means of measuring them than waiting for the actual events to occur.

Whatever the relationship between spatial behavior, dominance, and agonism, the results reported here suggest that it is possible to identify successful and unsuccessful breeders based on their sociospatial relationships in a breeding group long before the females in question have even conceived. While the measures suggested here may vary for other prinate species or for other breeding situations, behavioral monitoring of breeding females can contribute to a better understanding of the determinants of pregnancy outcome, in general, and can be a valuable aid to successful primate colony management.

\section{REFERENCE NOTE}

1. Fairbanks, L. A. Changes in the social behavior of adult females with infants in three primate species, Papio cynocephalus, Macaca nemestrina, and Saimiri sciureus. Unpublished PhD dissertation, 1974.

\section{REFERENCES}

DrickAMER, L. C. A ten year summary of reproductive data for free-ranging Macaca mulatta. Folia Primatologica, 1974, 21, 61-80.

Rosenblum, L. A. Some aspects of female reproductive physiology in the squirrel monkey. In L. A. Rosenblum \& R. W. Cooper (Eds.), The squirrel monkey. New York: Academic Press, 1968.

Rowell, T. E. Hierarchy in the organization of a captive baboon group. Animal Behaviour, 1966, 14, 430-443.

Sackett, G., Holm, R., \& LANDesman-Dwyer, S. Vulnerability for abnormal development: Pregnancy outcomes and sex differences in macaque monkeys. In $\mathbf{N}$. R. Ellis (Ed.), Aberrant development of infancy: Human and animal studies. New York: Halstead Press, 1975. Pp. 59-76.

VAN WAgENEN, V. Vital statistics from a breeding colony: Reproduction and pregnancy outcome in Macaca mulatta. Journal of Medical Primatology, 1972, 1, 3-28.

(Received for publication July 16, 1976.) 